\title{
Research Article \\ Effect of Wood Fillers on the Viscoelastic and Thermophysical Properties of HDPE-Wood Composite
}

\author{
M. Tazi, ${ }^{1}$ M. S. Sukiman, ${ }^{2}$ F. Erchiqui, ${ }^{1,3}$ A. Imad, ${ }^{2}$ and T. Kanit ${ }^{2}$ \\ ${ }^{1}$ Department of Applied Science, University of Quebec in Chicoutimi, Chicoutimi, QC, Canada G7H $2 B 1$ \\ ${ }^{2}$ Laboratoire de Mécanique de Lille, Université de Lille 1, Villeneuve d’Ascq Cedex, France \\ ${ }^{3}$ Laboratory of Plasturgy and Nanotechnology, University of Quebec in Abitibi-Témiscamingue, Rouyn-Noranda, \\ QC, Canada J9X 6V6
}

Correspondence should be addressed to F. Erchiqui; fouad.erchiqui@uqat.ca

Received 4 November 2015; Accepted 3 February 2016

Academic Editor: Matheus Poletto

Copyright (C) 2016 M. Tazi et al. This is an open access article distributed under the Creative Commons Attribution License, which permits unrestricted use, distribution, and reproduction in any medium, provided the original work is properly cited.

\begin{abstract}
Wood polymer composites (WPC) have well proven their applicability in several fields of the plasturgy sector, due to their aesthetics and low maintenance costs. However, for plasturgy applications, the characterization of viscoelastic behavior and thermomechanical and thermophysical properties of WPC with the temperature and wood filler contents is essential. Therefore, the processability of polymer composites made up with different percentage of wood particles needs a better understanding of materials behaviors in accordance with temperature and wood particles contents. To this end, a numerical analysis of the viscoelastic, mechanical, and thermophysical properties of composite composed of high density polyethylene (HDPE) reinforced with soft wood particles is evaluated.
\end{abstract}

\section{Introduction}

Nowadays, due to the environmental and economic concerns, many research activities are directed towards the development of new composites based on thermoplastic matrices with plants (or their residues) reinforcement [1]. Reinforcement of composites with natural fillers has several advantages in comparison to mineral fillers including lower density, being inexpensive, and being nonabrasive. In fact, high cellulose component of natural fillers makes them easily biodegradable and recyclable. Also, cellulose fillers possess a crystalline structure which plays a positive role in the composite reinforcement. As a consequence many researchers are interested in the development of new techniques for extraction and modification of cellulose fillers from bioresources [2-4].

In addition, cellulose has a reactive functionality that can react with coupling agents thus enhancing adhesion between the fiber and matrix [5]. Studies have also shown that the mechanical properties of composites are highly depending on the interaction between the thermoplastic matrix and distribution of loaded fillers [6]. While this interaction is well established, the loading force will be transferred from matrix to fillers more effectively.

On the other hand, the majority of modeling and simulating work of these biocomposites for their processing assumes constant thermal parameters of the materials, such as density and heat conductivity, or they do not take into account the special temperature dependency of the specific heat due to melting process. This is because the temperature dependence of these material parameters for biocomposites is not understood sufficiently so far. Since the rheological and deformation behaviors are strongly connected with the thermal behavior, it became obvious that these issues affect directly the accuracy of any simulation or modeling result.

In this regard, this work attempts to investigate, for thermoforming application, the process ability of composites made up of wood and a matrix of thermoplastic for six different proportions of wood fillers. To this end, a numerical analysis of the viscoelastic, thermomechanical, and thermophysical properties of composite composed of high density 


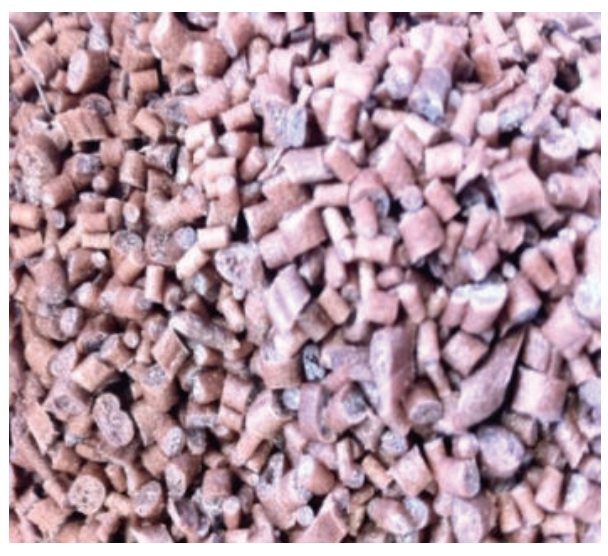

(a)

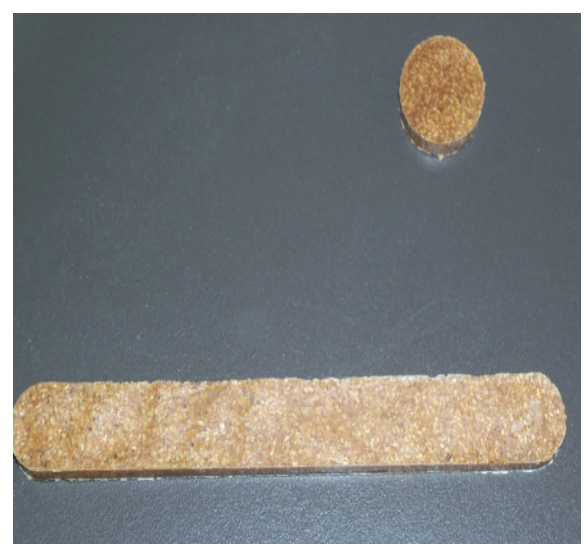

(b)

Figure 1: Pellets (a) and compression molded samples (b) of wood polymer composites.

TABLE 1: Average geometrical dimensions of fillers.

\begin{tabular}{lccc}
\hline $\begin{array}{l}\text { Area } \\
\left(\mathrm{mm}^{2}\right)\end{array}$ & $\begin{array}{c}\text { Long axis } \\
(\mathrm{mm})\end{array}$ & $\begin{array}{c}\text { Short axis } \\
(\mathrm{mm})\end{array}$ & $\begin{array}{c}\text { Shape ratio } \\
(\mathrm{L} / \mathrm{D})\end{array}$ \\
\hline 0.1154 & 0.574 & 0.302 & 1.97 \\
\hline
\end{tabular}

polyethylene (HDPE) reinforced with soft wood particles is evaluated.

\section{Materials and Methods}

2.1. Materials. The sawdust used in this study was supplied by Tembec sawmill located in Béarn (QC, Canada). It consists of $65 \%$ of white spruce (Picea glauca), $20 \%$ of black spruce (Picea mariana), and $15 \%$ of balsam fir (Abies balsamea). The particle size analysis of the sawdust is performed on more than 5000 particles using the apparatus FQA (Fiber Quality Analyser, Optest Equipment, Hawkesbury, Ontario). Table 1 shows the average geometry of sawdust. Wood flour was sieved to a diameter less than 700 microns ( $\varnothing<0.7 \mathrm{~mm}$ ). The polymer matrix is a high density polyethylene (Sclair A59), with the melting temperature of $138^{\circ} \mathrm{C}$ and density of $980 \mathrm{~kg} / \mathrm{m}^{3}$. The coupling agent is Fusabond 226 from Dupont, which is a polyethylene grafted with maleic anhydride (melting temperature $120^{\circ} \mathrm{C}$, melt flow index (MFI) of $1.5 \mathrm{~g} / 10 \mathrm{~min}$, under condition $190^{\circ} \mathrm{C}, 2.16 \mathrm{~kg}$ ). The used amount of coupling agent is $3 \%$ of total weight of composite. This amount is well known to improve the homogeneity of the mixture ensuring better distribution of fibers in the polymer matrix $[7,8]$. The sieved sawdust was previously dried under temperature of $105^{\circ} \mathrm{C}$ for 24 hours and stored in polyethylene bags. The residual moisture content in wood used for samples preparation is estimated by a second drying of $120^{\circ} \mathrm{C}$ for $24 \mathrm{~h}$. The wood humidity amount calculated from the mass of sawdust before and after drying was found less than 3\% wt.

2.2. Methods. The composite samples were prepared using a twin-screw counter-mixer (Haake Rheometrix with roller rotors) with angular speed of $90 \mathrm{rpm}$ at the temperature of $170^{\circ} \mathrm{C}$. In fact, this temperature is lower than wood fibers degradation temperature $\left(200^{\circ} \mathrm{C}\right)$ [9]. To prepare the composite material, first of all, Sclair A59 (HDPE polymer) and Fusabond (coupling agent) were mixed for 2 minutes in order to insure complete melting of the materials. Then, sawdust was added to the mixture and blended for 5 minutes. Six different sawdust proportions were investigated including $0 \mathrm{wt} \%, 20 \mathrm{wt} \%, 30 \mathrm{wt} \%, 40 \mathrm{wt} \%, 50 \mathrm{wt} \%$, and $60 \mathrm{wt} \%$ and the total mass of composite in mixing chamber is $148 \mathrm{~g}$. In the next step, flat disc samples were prepared by compression molding using a hot press at the temperature of $150^{\circ} \mathrm{C}$ (above melting temperature of the polymer, $138^{\circ} \mathrm{C}$ ) with aluminum mold plates. In order to make sure the mixture is softened properly, a preload was first applied for two minutes. This preload is also beneficial for removing possible accumulated air in the material. Then, loading on the material was continued up to $8 \mathrm{MPa}$ for 4 minutes to give the final circular shape of the samples with $20 \mathrm{~mm}$ diameter and $4 \mathrm{~mm}$ thickness (Figure 1).

\section{Viscoelastic Characterization of Biocomposites}

3.1. Constitutive Equation. The material deformation mechanisms that occur in plasturgy can be classified into two types: linear material response and nonlinearities due to large deformations. The linear properties refer to elastic modulus, viscosity, and deformation memory while the nonlinear part refers to damping due to large deformations.

Integral type viscoelastic models relate the true stress to strain history. These models are more appropriate for representing polymers at the semisolid or molten state. The Lodge model [10] has been developed for representing the viscoelastic deformation of viscoelastic polymers. For example, it can be used for the thermoforming of semisolid materials [1] or injection for molten state [10].

To handle the behavior of isotropic thermoplastic composite, we apply the Lodge constitutive model [10]. For this 


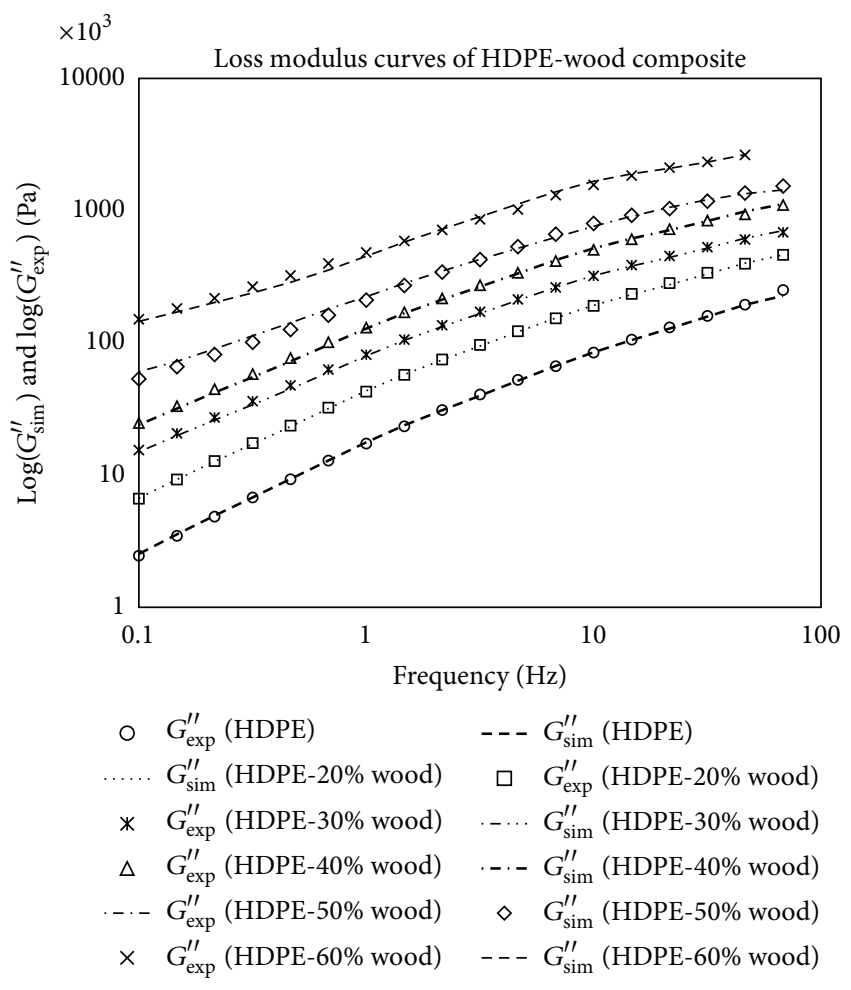

(a)

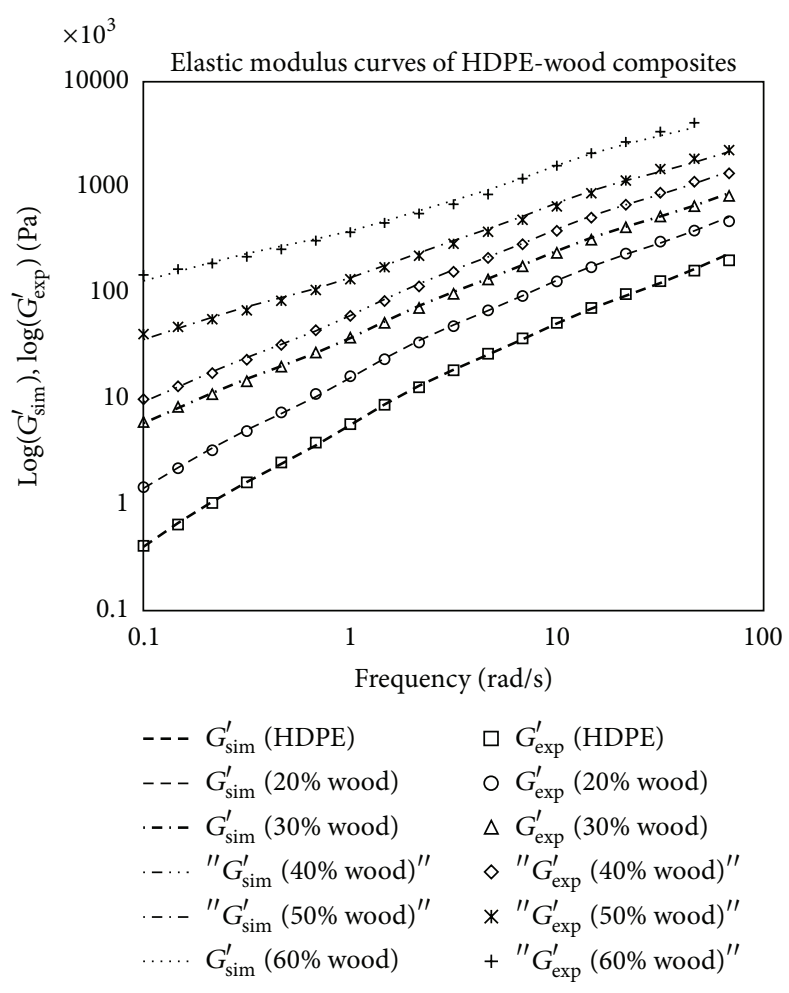

(b)

FIGURE 2: Dynamic modulus (loss modulus (a) and elastic modulus (b)) of WPC composites with different concentration of wood fillers at $T=170^{\circ} \mathrm{C}$.

model, the Cauchy stress tensor $\sigma(\mathbf{t})$ is related, at time $\mathbf{t}$, to the history of the Finger deformation tensor $\mathbf{B}(\tau, \mathbf{t})$ by

$$
\boldsymbol{\sigma}(t)=-p(t) \mathbf{I}+\int_{0}^{t} \sum_{k} \frac{g_{k}}{\tau_{k}} e^{-(t-\tau) / \tau_{k}} \frac{\partial \mathbf{B}(\tau, t)}{\partial \tau} d \tau,
$$

where the Finger tensor $\mathbf{B}$ is related to the right CauchyGreen deformation tensor $\mathbf{C}$ :

$$
\mathbf{B}=\mathbf{C}^{-1}=\left(\mathbf{F}^{T} \mathbf{F}\right)^{-1}
$$

F is the deformation gradient tensor, $p$ is the hydrostatic pressure, and $g_{k}$ and $\tau_{k}$ represent, respectively, the stiffness moduli and the relaxation time. The dependency of these models on temperature is accounted for by using the WLF function [11].

3.2. Characterization Techniques. The determination of material constants requires the use of different characterization techniques. The linear properties can be obtained from small amplitude oscillatory shear test $[12,13]$. This technique is used to determine the storage and loss moduli of the six composites (Figure 2). Data were collected at different flours percentage, in the Sclair A59 matrix, of 0\%, 20\%, $30 \%, 40 \%, 50 \%$, and $60 \%$. As shown, good superposition is obtained. The dynamic moduli curves for six composites have very different shapes but shifted in frequency.
From the dynamic data, the discrete relaxation spectra for six composites were determined employing a pattern search method which minimizes the objective function, $F$, defined:

$$
F=\sum_{i=1}^{N}\left[\frac{G_{i, \exp }^{\prime}-G_{i, \mathrm{fit}}^{\prime}}{G_{i, \exp }^{\prime}}\right]^{2}+\left[\frac{G_{i, \exp }^{\prime \prime}-G_{i, \mathrm{fit}}^{\prime \prime}}{G_{i, \exp }^{\prime \prime}}\right]^{2}
$$

where $N$ is the number of data points, $\left(G_{i, \exp }^{\prime}, G_{i, \exp }^{\prime \prime}\right)$ is available from the dynamic experiments, and $\left(G_{i, \text { fit }}^{\prime}, G_{i, \mathrm{fit}}^{\prime \prime}\right)$ denotes the best fit values on the basis of equations:

$$
\begin{aligned}
& G^{\prime}(\omega)=\sum_{i=1}^{N} \frac{g_{i} \lambda_{i}^{2} \omega^{2}}{1+\lambda_{i}^{2} \omega^{2}}, \\
& G^{\prime}(\omega)=\sum_{i=1}^{N} \frac{g_{i} \lambda_{i} \omega}{1+\lambda_{i}^{2} \omega^{2}} .
\end{aligned}
$$

The low-frequency behavior is dominated by the long relaxation times and the high-frequency response is controlled by the short relaxation times.

This representation makes it possible to describe the linear viscoelastic behavior over a wide range of time values by means of only a few constants. The relaxation strengths $g_{k}$, which represent the contribution to rigidity associated with relaxation times $\tau_{k}$, are listed in Table 2 . 
TABLE 2: Relaxation spectrum at $170^{\circ} \mathrm{C}$ for WPC.

\begin{tabular}{lcccccc}
\hline \% wood fillers & $0 \mathrm{wt} \%$ & $20 \mathrm{wt} \%$ & $30 \mathrm{wt} \%$ & $40 \mathrm{wt} \%$ & $50 \mathrm{wt} \%$ & $60 \mathrm{wt} \%$ \\
\hline$\tau_{k}$, sec & $g_{k}, \mathrm{MPa}$ & $g_{k}, \mathrm{MPa}$ & $g_{k}, \mathrm{MPa}$ & $g_{k}, \mathrm{MPa}$ & $g_{k}, \mathrm{MPa}$ & 1.1246 \\
0.001 & 0.181 & 0.3314 & 0.4649 & 0.6811 & 0.4343 & 0.2605 \\
0.01 & 0.0635 & 0.1219 & 0.1769 & 0.1696 & 0.2596 & 0.4987 \\
0.1 & 0.0298 & 0.0655 & 0.1083 & 0.1029 & 0.1249 & 0.4685 \\
1 & 0.011 & 0.0302 & 0.0566 & 0.061 & 0.1166 \\
10 & 0.0033 & 0.015 & 0.0344 & 0.3276 \\
\hline
\end{tabular}

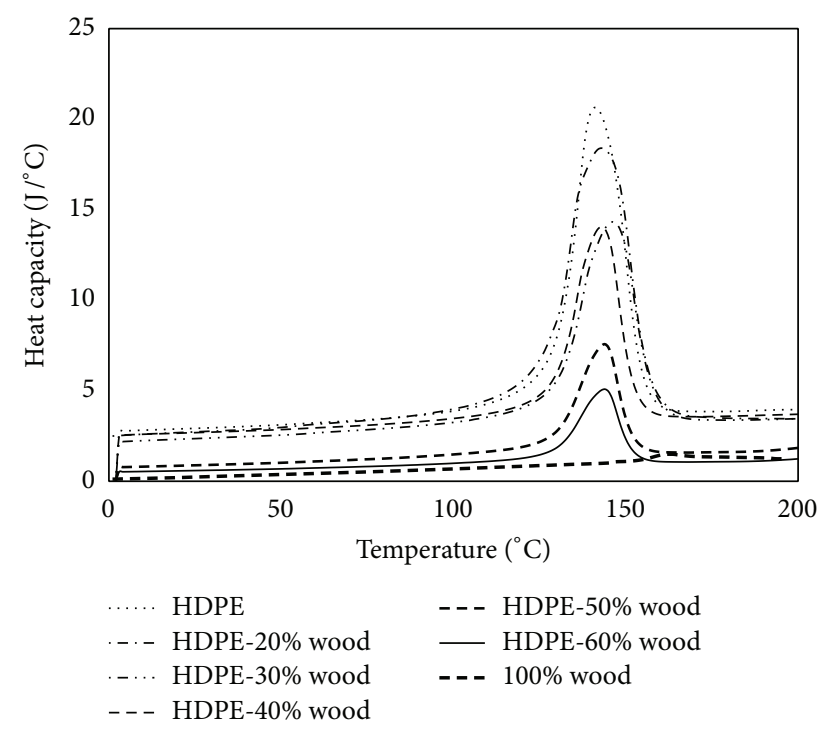

FIGURE 3: Change of heat capacity of HDPE-wood composite as function of temperature.

\section{Measurement of Heat Capacity and Specific Volume as Functions of Fillers Contents and Temperature}

4.1. Heat Capacity. Data curves of DSC analyses were used to evaluate the heat capacity of biocomposites. In Figure 3 we show the variation of specific heat capacity of the biocomposites with different fillers content as a function of temperature. We noticed that, during the melting phase, the variation of this parameter $\left(\Delta C_{p}\right)$ of HDPE-wood composites decreased compared to the matrix, for polyethylene is estimated to value $14.36 \mathrm{~J} / \mathrm{g} \cdot{ }^{\circ} \mathrm{C}$ and for HDPE-60\% wood fillers are equal to $6.7 \mathrm{~J} / \mathrm{g} .{ }^{\circ} \mathrm{C}$ as shown in Figure 3. It could be interpreted in the ways that the wood fillers act as a hindrance of molecular chains mobility close to melting temperature. These results are similar to those reported in many studies on natural fillers polymers composites. Bendahou and coauthors have investigated the effect of filler content and coupling agent on physical properties of short palm tree fibers polyolefin composites [13]. They report a slight increase of melting temperature independently of the percentage of natural fillers and also a considerable improvement in the structural arrangement of the polymers when the concentration of reinforcements increases. According to the authors the natural

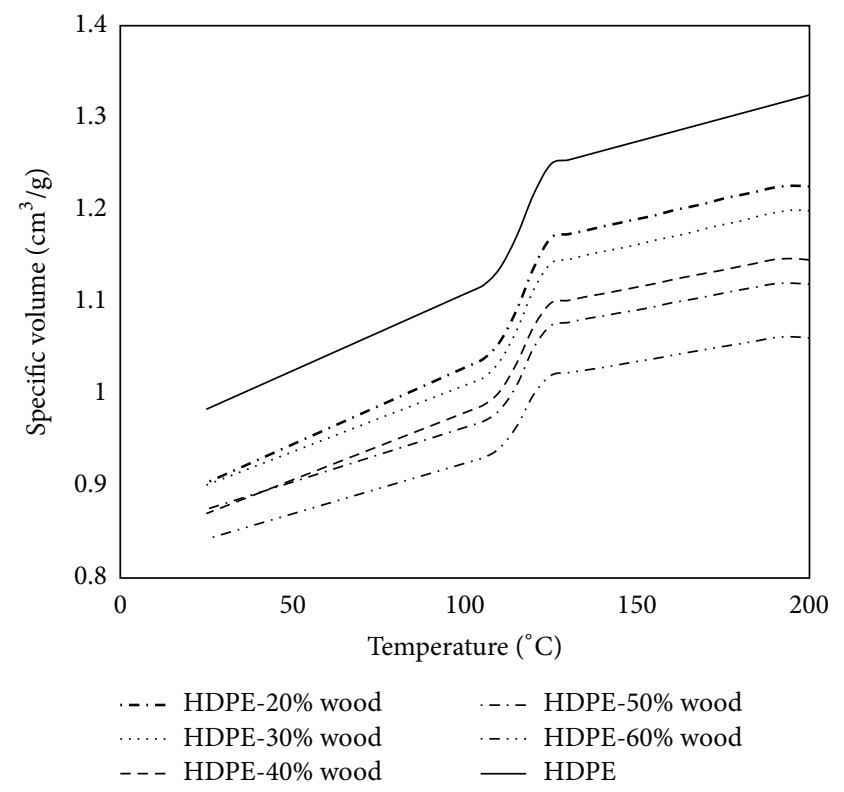

FIGURE 4: Specific volume variation as a function of filler contents.

fibers in the polymers act as nucleation site promoting a high degree of crystallinity of the polymer chains around the fibers.

4.2. Specific Volume. High temperature gradient accumulated in biocomposite during shaping process leads to a high residual stresses. This residual stress results generally in geometric instability of material. Specific volume changes of the biocomposites can be used as an index to prevent geometric instability through the processing. Also numerical simulation of composite behavior, based on temperature, requires an accurate description of specific volume changes of biocomposite as a function of temperature. In this regard, we study the variation of specific volume changes as function of temperature and filler content. It is visible from Figure 4 that the specific volume increases with the temperature and decreases while the wood fillers increase. The maximum change takes place during the melting phase of polymer at a transition temperature range of about 100 up to $130^{\circ} \mathrm{C}$. This is mainly due to crystallinity effects at this stage. Also, in cases of composites with high contents, the density of wood particles per unit volume increases and the level of interaction between wood particles became also important. 
TABLE 3: Linear regression of specific capacity according to the temperature and wood fillers.

\begin{tabular}{|c|c|c|c|c|c|c|c|c|}
\hline \multirow[t]{2}{*}{ Composites } & \multicolumn{3}{|c|}{$\begin{array}{c}C_{p}-C_{p_{0}}=a \cdot T \\
0<T<80^{\circ} \mathrm{C}\end{array}$} & \multicolumn{5}{|c|}{$\begin{array}{c}C_{p}-C_{p_{1}}=\frac{A}{\omega \sqrt{\pi / 2}} \cdot \exp ^{-2\left(T-T_{m}\right)^{2} /(\omega)^{2}} \\
81^{\circ} \mathrm{C}<T<200^{\circ} \mathrm{C}\end{array}$} \\
\hline & $C_{p_{0}}$ & $a \cdot 10^{4}$ & $R^{2}$ & $C_{p_{1}}$ & $T_{m}$ & A & $\omega$ & $R^{2}$ \\
\hline HDPE & 2.73 & 89 & 98 & 4.02 & 138.80 & 283.5 & 13.53 & 0.99 \\
\hline HDPE-20\% wood & 2.45 & 116 & 98 & 3.81 & 140.98 & 315.5 & 16.79 & 0.98 \\
\hline HDPE-30\% wood & 2.52 & 77 & 99 & 3.43 & 141.72 & 205.6 & 14.97 & 0.98 \\
\hline HDPE- $40 \%$ wood & 2.16 & 93 & 99 & 3.64 & 138.64 & 161.9 & 12.40 & 0.98 \\
\hline HDPE- $50 \%$ wood & 0.75 & 62 & 99 & 1.64 & 139.06 & 83.76 & 11.58 & 0.97 \\
\hline HDPE- $60 \%$ wood & 0.50 & 42 & 99 & 1.10 & 139.06 & 56.19 & 11.58 & 0.97 \\
\hline
\end{tabular}

TABLE 4: Linear regression of specific volume according to the temperature and wood fillers.

\begin{tabular}{|c|c|c|c|c|c|c|c|c|}
\hline \multirow[t]{3}{*}{ Composites } & \multicolumn{5}{|c|}{$\vartheta=A_{2}+\frac{\left(A_{1}-A_{2}\right)}{1+\exp ^{\left(T-T_{0}\right) / \mathrm{d} T}}$} & \multicolumn{3}{|c|}{$\vartheta-\vartheta_{0}=a \cdot T$} \\
\hline & & & $0<T$ & & & & $<T<2$ & \\
\hline & $A_{1}$ & $A_{2}$ & $T_{0}$ & $\mathrm{~d} T$ & $R^{2}$ & $\vartheta_{0}$ & & $R^{2}$ \\
\hline HDPE & 0.97 & 80 & 302 & 31 & 0.98 & 1.12 & 10.10 & 0.99 \\
\hline HDPE- $20 \%$ wood & 0.89 & 79 & 302 & 31 & 0.98 & 1.06 & 8.05 & 0.99 \\
\hline HDPE-30\% wood & 0.89 & 61 & 284 & 29 & 0.98 & 1.04 & 8.11 & 0.98 \\
\hline HDPE- $40 \%$ wood & 0.85 & 62 & 303 & 32 & 0.98 & 1.01 & 6.92 & 0.98 \\
\hline HDPE-50\% wood & 0.86 & 79 & 292 & 28 & 0.98 & 0.99 & 6.53 & 0.98 \\
\hline HDPE- $60 \%$ wood & 0.83 & 65 & 300 & 29 & 0.98 & 0.94 & 1.91 & 0.98 \\
\hline
\end{tabular}

4.3. Mathematical Representation of Thermophysical Properties. For the purpose of processing modeling and numerical simulation, it is essential to have mathematical expressions of thermophysical properties of polymer based composites. Hence, in order to have analytical representations of heat capacity and specific volume based on the temperature and wood filler content, some obtained experimental data were used. In this case, based on a regression analysis the temperature region was divided into two different regions (inside and outside of the transition zone). The equations in the tables represent the best estimates of the measured experimental data. The values of the required regression parameters are listed in Table 3 for heat capacity and in Table 4 for specific volume.

\section{Conclusion}

Wood polymer composites (WPC) have well proven their applicability in several fields of the plasturgy sector, due to their aesthetics and low maintenance costs. However, for plasturgy applications, the processability of polymer composites made up with different percentage of wood particles needs a better understanding of materials behaviors in accordance with temperature and wood particles contents. In this regard, we attempt in this work to perform a characterization of viscoelastic, rheological, and thermophysical properties of WPC.

Our results indicate that the rheological and the thermomechanical properties of composites vary according to wood fillers content and temperature. Composites behavior became more elastic than viscous while wood particles percentage increases.

Also, thermophysical properties of composites (specific heat capacity and specific volume) change as function of temperature and filler content. The maximum variations take place during the melting phase of polymer. A mathematical representation of the variation of thermophysical parameters according to temperature and wood fillers is performed. This allowed us to predict the thermophysical behavior of composite at temperatures and wood fillers where it is difficult to measure experimentally.

\section{Competing Interests}

The authors declare that they have no competing interests.

\section{References}

[1] F. Erchiqui, F. Godard, A. Gakwaya, A. Koubaa, M. Vincent, and H. Kaddami, "Engineering investigations on the potentiality of the thermoformability of HDPE charged by wood flours in the thermoforming part," Polymer Engineering and Science, vol. 49, no. 8, pp. 1594-1602, 2009.

[2] A. Bendahou, Y. Habibi, H. Kaddami, and A. Dufresne, "Physico-chemical characterization of palm from Phoenix Dactylifera-L, preparation of cellulose whiskers and natural rubber-based nanocomposites," Journal of Biobased Materials and Bioenergy, vol. 3, no. 1, pp. 81-90, 2009.

[3] A. K. Bledzki and O. Faruk, "Wood fibre reinforced polypropylene composites: effect of fibre geometry and coupling agent on 
physico-mechanical properties," Applied Composite Materials, vol. 10, no. 6, pp. 365-379, 2003.

[4] H. Kaddami, A. Dufresne, B. Khelifi et al., "Short palm tree fibers-thermoset matrices composites," Composites Part A: Applied Science and Manufacturing, vol. 37, no. 9, pp. 1413-1422, 2006.

[5] O. Faruk, A. K. Bledzki, H.-P. Fink, and M. Sain, "Biocomposites reinforced with natural fibers: 2000-2010," Progress in Polymer Science, vol. 37, no. 11, pp. 1552-1596, 2012.

[6] A. K. Bledzki, S. Reihmane, and J. Gassan, "Thermoplastics reinforced with wood fillers: a literature review," PolymerPlastics Technology and Engineering, vol. 37, no. 4, pp. 451-468, 1998.

[7] T. J. Keener, R. K. Stuart, and T. K. Brown, "Maleated coupling agents for natural fibre composites," Composites Part A: Applied Science and Manufacturing, vol. 35, no. 3, pp. 357-362, 2004.

[8] N. Sombatsompop, C. Yotinwattanakumtorn, and C. Thongpin, "Influence of type and concentration of maleic anhydride grafted polypropylene and impact modifiers on mechanical properties of PP/wood sawdust composites," Journal of Applied Polymer Science, vol. 97, no. 2, pp. 475-484, 2005.

[9] C. Burgstaller, "Processing of thermal sensitive materials-a case study for wood plastic composites," Monatshefte für ChemieChemical Monthly, vol. 138, no. 4, pp. 343-346, 2007.

[10] A. S. Lodge, Elastic Liquids, Academic Press, New York, NY, USA, 1964.

[11] M. L. Williams, R. F. Landel, and J. D. Ferry, “The temperature dependence of relaxation mechanisms in amorphous polymers and other glass-forming liquids," Journal of the American Chemical Society, vol. 77, no. 14, pp. 3701-3707, 1955.

[12] F. Erchiqui, F. Godard, A. Koubba, M. Vincent, and H. Kaddami, "Investigation of relaxation properties and potentiality of the thermoformability of HDPE charged by wood flours," Journal of Reinforced Plastics and Composites, vol. 28, no. 10, pp. 1153$1168,2009$.

[13] A. Bendahou, H. Kaddami, H. Sautereau, M. Raihane, F. Erchiqui, and A. Dufresne, "Short palm tree fibers polyolefin composites: effect of filler content and coupling agent on physical properties," Macromolecular Materials and Engineering, vol. 293, no. 2, pp. 140-148, 2008. 

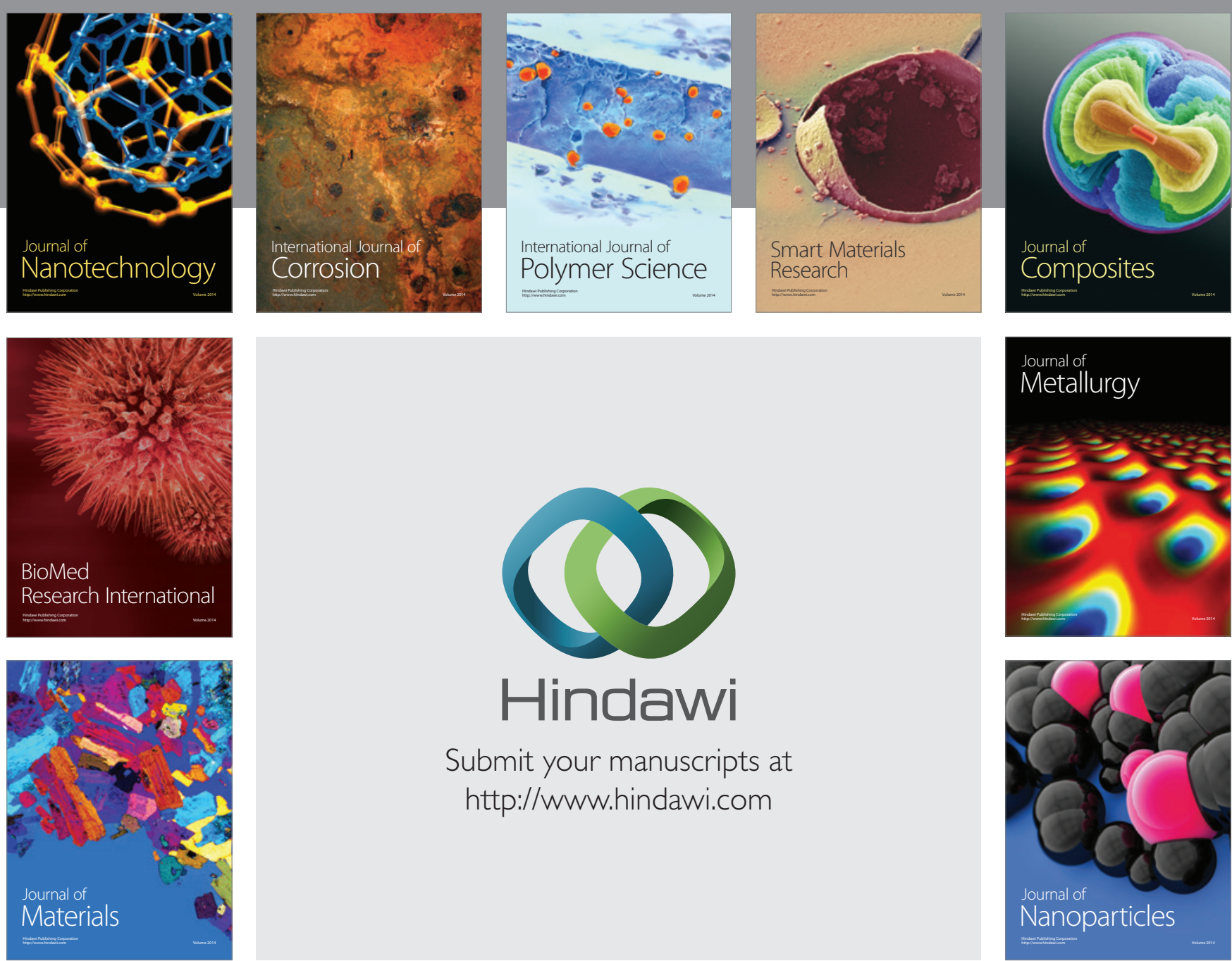

\section{Hindawi}

Submit your manuscripts at

http://www.hindawi.com

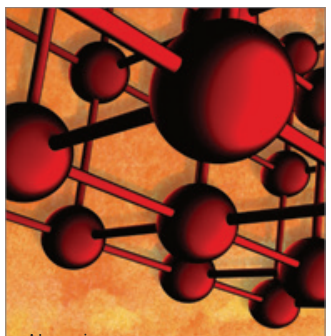

Materials Science and Engineering
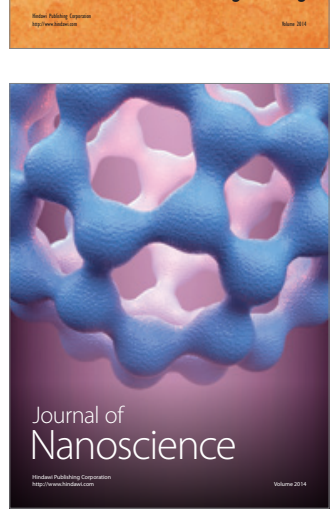
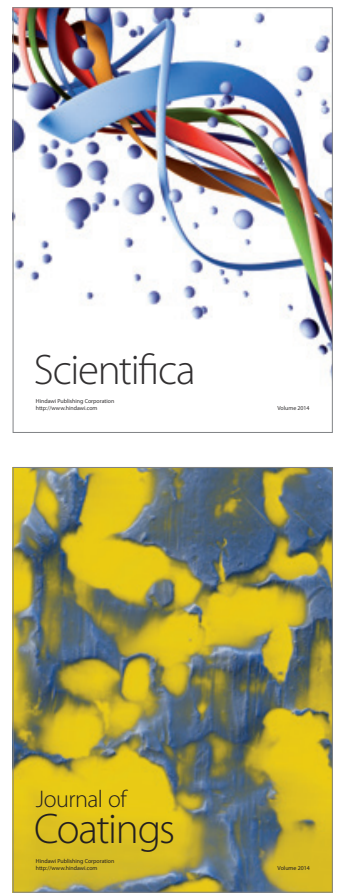
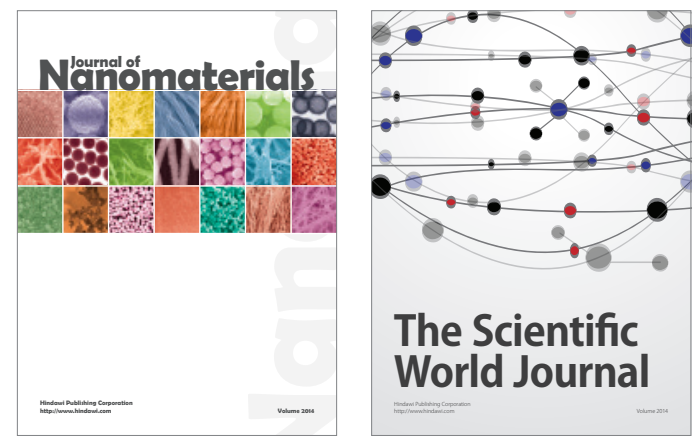

The Scientific World Journal
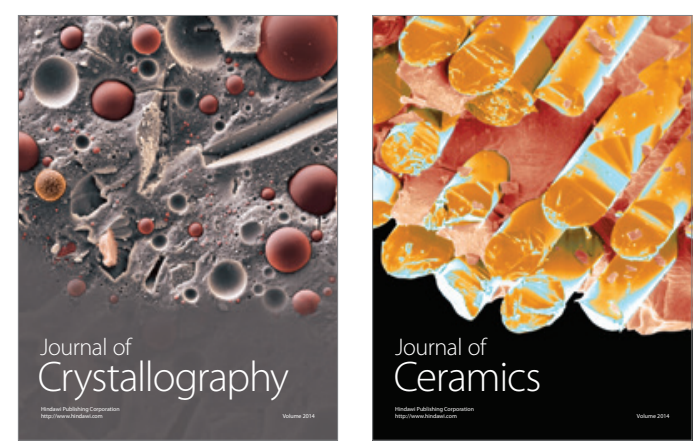
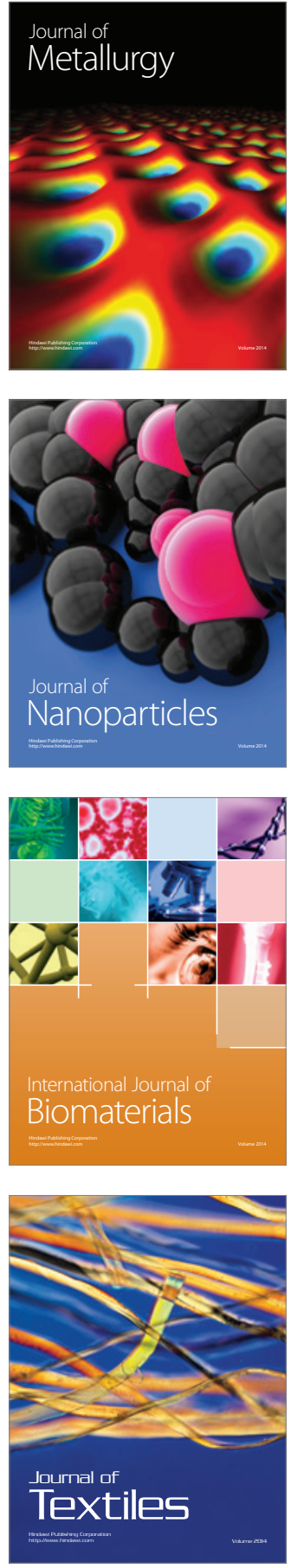